\title{
Classification System of Indonesian Language Thesis Documents in Computer Science Department using K-Means Algorithm
}

\author{
Boldson Herdianto Situmorang, Rezky Ramadhan Alkausar, Prihastuti Harsani
}

\begin{abstract}
Thesis is a scientific paper created by the student as a final requirement on his final academic education to earn a bachelor's degree. Students of the Computer Science Department at Pakuan University are faced with the difficulty of finding the previous thesis references to determine the desired thesis theme because the clustering of the thesis documents is set based on the writing year only and not based on the theme classifications which includes Software Engineering, Hardware Programming, Artificial Intelligence, and Network Computer. A computer based system will be developed where the data in the Thesis document will be processed through text pre-processing which aims to convert unstructured document data into structured so that it can be read by the system, then grouped using K-Means Algorithm.
\end{abstract}

Index Terms: Classification System, Thesis Documents, K-Means Algorithm

\section{INTRODUCTION}

Students of the Computer Science Department at Pakuan University are faced with the difficulty of finding the previous thesis references to determine the desired thesis theme because the clustering of the thesis documents is set based on the writing year only and not based on the theme classifications. It is time consuming for readers to retrieve relevant information from unstructured document collection. It is easier and less time consuming to find documents from a large collection when the collection is ordered or classified by group or category.

R. Kaur and A. Kaur proposed the classification of documents using K-Means Algorithm and Neural Network to achieve the similarity between documents. The obtained results are very acceptable having good recall, precision rate having graph values of precision rate [3].

This paper discusses the implementation of K-Means Algorithm for thesis document classification. We have experimented with different representation using text pre-processing process which aims to convert unstructured document data into structured so that it can be read by the system.

Revised Manuscript Received on April 25, 2019.

Boldson Herdianto Situmorang, Department of Computer Science, Pakuan Bogor University, 16143, Indonesia.

Rezky Ramadhan Alkausar, Department of Computer Science, Pakuan Bogor University, 16143, Indonesia.

Prihastuti Harsani, Department of Computer Science, Pakuan Bogor University, 16143, Indonesia.

\section{RESEARCH AND METHOD}

The Thesis documents used in this study are from 2013 to 2016. Data of Thesis title used in this research consists of four classes Software Engineering, Hardware Programming, Artificial Intelligence, and Computer Network. A total of 218 titles were used in this study. Data of thesis title is then divided into two parts, 168 titles as data of training and as many as 50 titles as data of test.

Every data of Thesis document will be through the process of text pre-processing that aims to change data of unstructured document into structured [1] so that it can be read by the system, then do the grouping using k-means algorithm.

a. Case Folding, is the process of transforming text into lower case.

b. Tokenization, is the process of separating words into several tokens.

c. Stopword filter, is the process of removing words that do not affect the contents of the document.

d. TF.IDF, is the term weighting method using term frequency.

$$
I D F=\log \left(\frac{n}{d f}\right)
$$

Where $n=$ the total number of document

$D f=$ frequency of occurrence of words in each document

After all text pre-processing steps are done then can further implement k-means algorithm, as follows [7]:

- Randomly select 'c' cluster centers.

- Calculate the distance between each data point and cluster centers using Euclidean Distance formula [2]: $D(i, j)=$

$\sqrt{\left(\left|x_{i 1}-x_{j 1}\right|^{2}+\left|x_{i 2}-x_{j 2}\right|^{2}+\cdots+\left|x_{i p}-x_{j p}\right|^{2}\right)}$

Where: $D(i, j)=$ distance of $i^{\text {th }}$ data to cluster center $\mathrm{j}$

$\mathrm{X}_{\mathrm{ik}}=$ the $\mathrm{i}^{\text {th }}$ on the $\mathrm{k}^{\text {th }}$ data atribut

$\mathrm{X}_{\mathrm{jk}}=$ the $\mathrm{j}^{\text {th }}$ center point on $\mathrm{k}^{\text {th }}$ data atribut

- Assign the data point to the cluster center whose distance from the cluster center is minimum of all the cluster centers.

- Recalculate the new cluster center.

Published By:

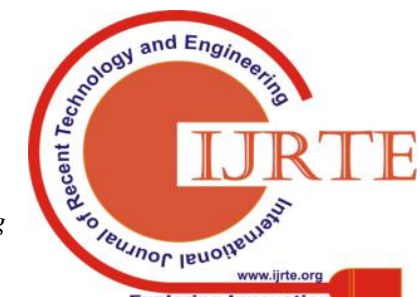




\section{Classification System of Indonesian Language Thesis Documents in Computer Science Department Using K-Means Algorithm}

\section{RESULTS AND DISCUSSION}

\section{A. File Conversion}

Converting the data of thesis documents to txt is the preliminary step of work before text pre-processing so that the text file can be read using Rapid Miner application.

\section{B. Text Pre-processing}

Here are some examples data of thesis documents:
$1^{\text {st }}$ Document (D1)
: Making of Bogor Diskominfo Website

$2^{\text {nd }}$ Document (D2)

Automatic Wiper Model Using Rain Sensor and Microcontroller of Atmega 328

$3^{\text {rd }}$ Document (D3)

: Automatic Clothesline Model Using Ldr Sensor, Rain Sensor, and Microcontroller of Atmega 328

$4^{\text {th }}$ Document (D4) : Analysis and Mapping of Landslide Prone Roads Using Arcgis 9.3

The preliminary results of the text preprocessing of all the above data of sample:

$1^{\text {st }}$ Document (D1) : bogor|districs|diskominfo|website|

$2^{\text {nd }}$ Document (D2) :

automatic|wiper|model|rain|sensor|microcontroller|atme ga|328

$3^{\text {rd }}$ Document (D3) :

automatic|clothesline|model||ldr|sensor|rain|microcontrol ler|atmega|328

$4^{\text {th }}$ Document (D4) :

analysis|mapping|landslide|prone|roads|arcgis $\mid 9.3$

The next process is to weighting the results of the preprocessing text with the TF.IDF method. The TF.IDF

Table 1. TF.IDF weighting

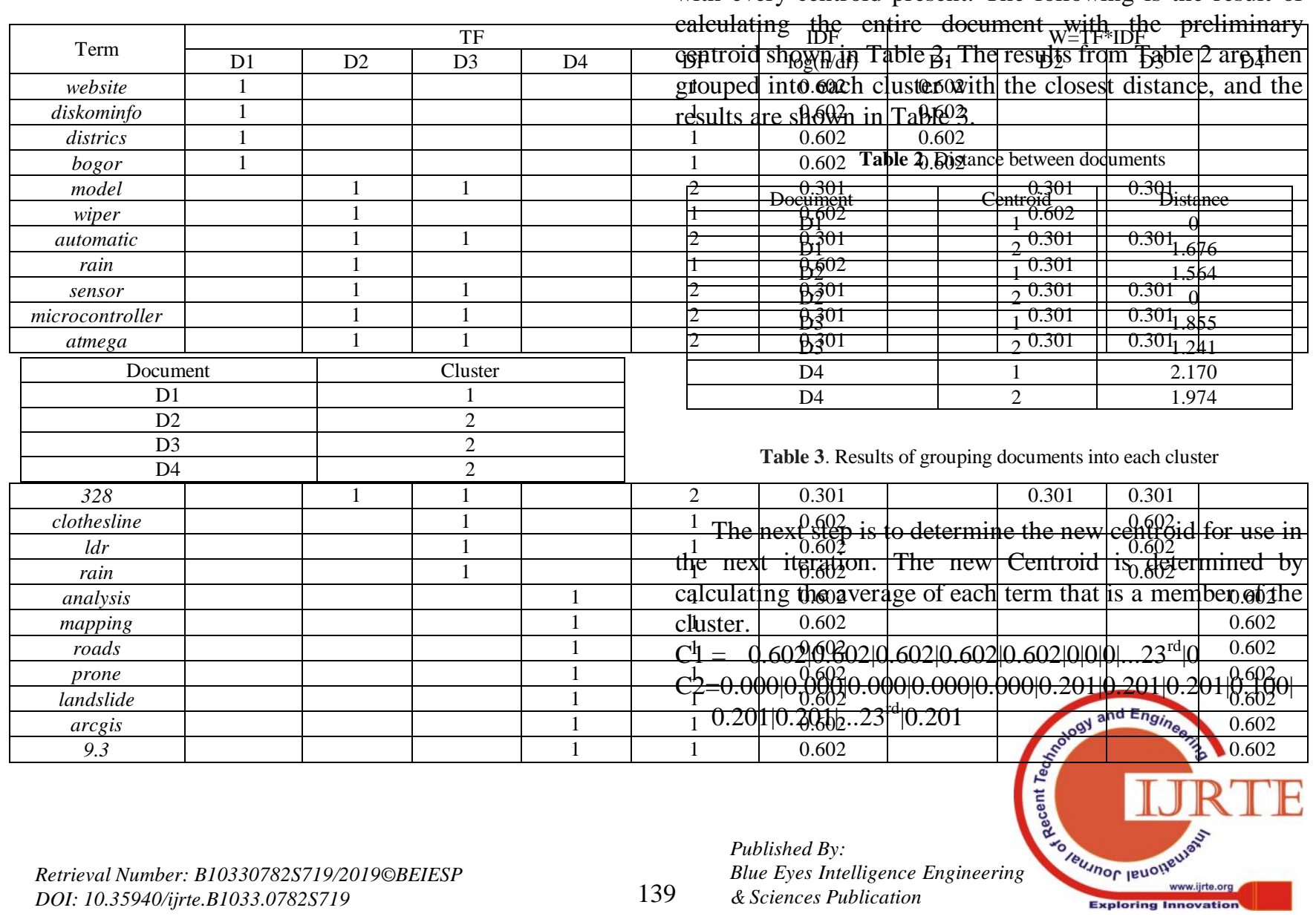

method is implemented by calculating the word frequency of each document using Equation (1).

\begin{tabular}{|ll|}
\hline Data Sample: & Making of Bogor Districs Diskominfo \\
& Website \\
Case Folding: & making of bogor districs diskominfo website \\
Tokenization: & making of|bogor|districs|diskominfo|website \\
Filter Stopword: & |bogor|districs|diskominfo|website
\end{tabular}

Figure 1. Text pre-processing on D1

\section{Implementation of K-Means Algorithm}

The implementation of K-Means algorithm begins by determining cluster [4], by still referring to the data of sample of the text pre-processing above, it is determined that the cluster value (c) is 2 .

The preliminary centroid determined randomly is D1 and $\mathrm{D} 2$ then the preliminary centroid value is as follows:

$\mathrm{D} 1 / \mathrm{C} 1=0.602|0.602| 0.602|0.602| 0.602|0| 0|0| . .23^{\text {rd }} \mid 0$

$\mathrm{D} 2 / \mathrm{C} 2=$

$0|0| 0|0| 0|0.301| 0.602|0.301| 0.301|0.301| 0.301|0.301| 0.301|0|$ $0\left|\ldots 23^{\text {rd }}\right| 0$

These values are obtained from the weighting process with TF.IDF.

The next step is to do the preliminary iteration by calculating the distance between documents using the Equation (2). Here is an example of calculating the distance between $\mathrm{D} 1$ and $\mathrm{C} 1$ :

$$
\begin{aligned}
& D(D 1, C 1)=\sqrt{\left(0.602-\left.0.602\right|^{2}+|0.602-0.602|^{2}+\cdots+|0-0|^{2}\right)} \\
& D(D 1, C 1)=0
\end{aligned}
$$

The distance calculation is performed on each document with every centroid present. The following is the result of ealettating the entire doetment $w^{\text {with }}$ the preliminary gitouped intoresh clusterarith the closest distance, and the

Table 3. Results of grouping documents into each cluster 
Referring to the new centroid, the next iteration is done by calculating the same distance as the previous step until it grouped the distance to each cluster. Referring to the new centroid, the next iteration is done by calculating the same distance as the previous step until it grouped the distance to each cluster. If the cluster results are different from the previous one then specify the next centroid and calculate the distance between the documents, if the cluster is the same as before then the iteration process is completed.

Of the 219 Thesis documents data tested resulted in 4 clustering of data based on the cluster with the characteristic value closest to the closest distance to the center of the cluster. $1^{\text {st }}$ cluster is a group of software engineering, $2^{\text {nd }}$ cluster is a group of artificial intelligence, $3^{\text {rd }}$ cluster is a group of hardware programming and $4^{\text {th }}$ cluster is a group of computer networks. Table 4 shows the clustering result of thesis documents.

Table 4. Clustering result of thesis documents

\begin{tabular}{|l|c|}
\hline \multicolumn{1}{|c|}{ Cluster } & $\begin{array}{c}\text { Number of } \\
\text { Document }\end{array}$ \\
\hline $1^{\text {st }}$ Cluster (Software Engineering) & 70 \\
\hline $2^{\text {nd }}$ Cluster (Artificial Intelligence) & 69 \\
\hline $3^{\text {rd }}$ Cluster (Hardware Programming) & 45 \\
\hline $4^{\text {th }}$ Cluster (Computer Networks) & 35 \\
\hline
\end{tabular}

Table 5. Manually clustering result of thesis documents

\begin{tabular}{|c|c|c|c|c|c|}
\hline Theme & Numbe & of docun & nt for ea & cluster & $\begin{array}{c}\text { Total } \\
\text { Number of }\end{array}$ \\
\hline $\begin{array}{l}\text { Software } \\
\text { Engineering }\end{array}$ & $\begin{array}{c}61 \\
(\mathrm{C} 1)\end{array}$ & $\begin{array}{c}24 \\
(\mathrm{C} 2)\end{array}$ & $\begin{array}{c}2 \\
(\mathrm{C} 3)\end{array}$ & $\begin{array}{c}4 \\
(\mathrm{C} 4)\end{array}$ & 91 \\
\hline $\begin{array}{l}\text { Artificial } \\
\text { Intelligence }\end{array}$ & $\begin{array}{c}3 \\
(\mathrm{C} 1)\end{array}$ & $\begin{array}{c}40 \\
(\mathrm{C} 2)\end{array}$ & $\begin{array}{c}2 \\
(\mathrm{C} 3)\end{array}$ & $\begin{array}{c}27 \\
(\mathrm{C} 4)\end{array}$ & 72 \\
\hline $\begin{array}{l}\text { Hardware } \\
\text { Programming }\end{array}$ & $\begin{array}{c}5 \\
(\mathrm{C} 1)\end{array}$ & $\begin{array}{c}4 \\
(\mathrm{C} 2)\end{array}$ & $\begin{array}{c}40 \\
(\mathrm{C} 3)\end{array}$ & $\begin{array}{c}2 \\
(\mathrm{C} 4)\end{array}$ & 51 \\
\hline $\begin{array}{l}\text { Computer } \\
\text { Networks }\end{array}$ & $1(\mathrm{C} 1)$ & $1(\mathrm{C} 2)$ & $1(\mathrm{C} 3)$ & $2(\mathrm{C} 4)$ & 5 \\
\hline
\end{tabular}

To calculate the quality of algorithms, precision $(\mathrm{P})$, recall (R), and F-Score is used [6] by comparing the results of manually grouping (Table 5) with the result of system grouping. Precision is comparison of the number of relevant documents obtained through the system with the number of relevant documents obtained manually; recall is the fraction of actual objects that were identified, and F-Score is the harmonic mean of precision and recall and will tries to give a good combination of the two [5].

$$
\begin{gathered}
P(\text { precision })=\frac{T P}{T P+F P} \\
R(\text { recall })=\frac{T P}{T P+T M} \\
F-\text { Score }=\frac{2 * R+P}{R+P}
\end{gathered}
$$

Where: TP (True Positive $)=$ relevant documents are found

FP $($ False Positive $)=$ irrelevant documents are found FN (False Negative $)=$ relevant documents are not found

Table 6. The average performance of k-mean algorithm

\begin{tabular}{|l|c|c|c|c|}
\hline \multicolumn{1}{|c|}{ Metric } & C1 & C2 & C3 & C4 \\
\hline Precision & 0.8714 & 0.5797 & 0.8889 & 0.0571 \\
\hline Recall & 0.6703 & 0.5556 & 0.7843 & 0.4000 \\
\hline F-Score & 0.7577 & 0.5674 & 0.8333 & 0.0999 \\
\hline
\end{tabular}

\section{The Analysis of Results}

The following chart obviously shows the performance of $\mathrm{k}$-mean algorithm. This provides good precision for $\mathrm{C} 1$ and $\mathrm{C} 3$, but not for $\mathrm{C} 2$ and $\mathrm{C} 4$. This is because the data of thesis document title which is very diverse and relevant has characteristics which are almost the same as other themes, such as between C1 (Software Engineering) and C2 (Artificial Intelligence), as well as at least the data of thesis document titles related to C4 (Computer Network).

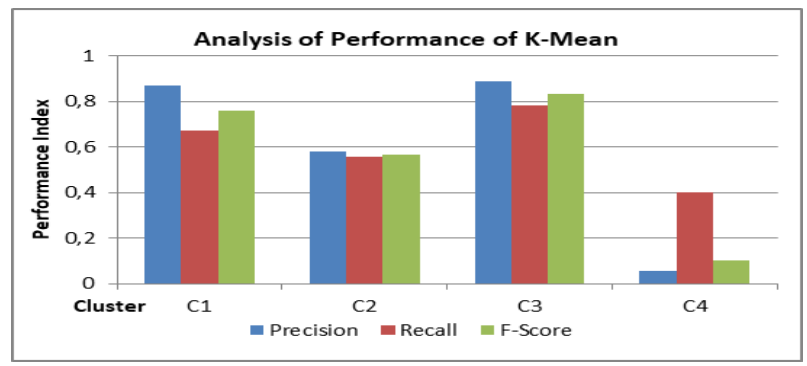

Fig. 2. Performance of k-mean algorithm

\section{CONCLUSION}

The classification of thesis documents can be performed using k-means algorithm method. Through this research proved that the model of k-means algorithm can help the process of grouping various themes of thesis into a group of themes with the same characteristics. Preferably before implementing the k-means algorithm, do the text pre-processing first.

The k-means algorithm classifies based on the similarity of characteristics obtained through the distance between the cluster center and the document being tested. If more number of words are stored, more word frequency will be compared to test data from text, this will result in the longer time required for the classification process. Incompatibility of documents with the theme is due to the same word and the weighted value of words from other themes is greater, this causes the grouping of documents more closely to other themes.

\section{ACKNOWLEDGMENT}

The authors would like to thank Faculty of Mathematics and Natural Sciences, Pakuan University, for financial support.

\section{REFERENCES}

1. S. Kannan and V. Gurusamy. "Preprocessing Techniques for Text Mining." International Journal of Computer Science \& Communication Networks, vol. 5 (1), pp. 7-16.

2. H. L. Sari, D. Suranti and L. N. Zulita, "Implementation of k-means clustering method for electronic learning model." Journal of Physics: Conf. Series, vol. 930, 012021, 2017.

3. R. Kaur and A. Kaur, "Text document clustering and classification using k-means algorithm and neural networks" Indian Journal of Science and Technology, vol 9 (40), 78-96, 2016.

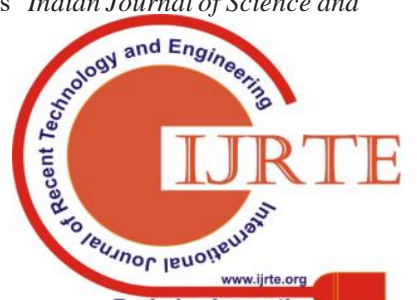


Classification System of Indonesian Language Thesis Documents in Computer Science Department Using K-Means Algorithm

5. A. Šilić, M. F. Moens, L. Žmakand B. D. Bašić. "Comparing document classification schemes using k-means clustering." In International Conference on Knowledge-Based and Intelligent Information and Engineering Systems. pp. 615-624, 2008.

6. R. Malviya and P. Jain. "A Novel Text Categorization Approach based on K-means and Support Vector Machine.” International Journal of Computer Applications, vol. 130 (14), pp. 1-7, 2015.

7. S. T. Deokar. "Text Documents Clustering using K Means Algorithm". International Journal of Technology and Engineering Science, vol 1 (4), pp. 282-286, 2013.

8. E. Laxmi Lydia, P. Govindaswamy, SK. Lakhsmanaprabu, D. Ramya "Document Clustering Based On Text Mining K-Means Algorithm Using Euclidean Distance Similarity". Journal of Advanced Research in Dynamical and Control System, vol 10 (2), pp. 208-214, 2018. 